\title{
Evaluation of perioperative nutritional status with subjective global assessment method in patients undergoing gastrointestinal cancer surgery
}

Aylin Erdim, Ahmet Özdemir Aktan

ABSTRACT

Cite this paper as:

Erdim A, Aktan AÖ. Evaluation of perioperative nutritional status with subjective global assessment method in patients undergoing gastrointestinal cancer surgery. Turk J Surg 2017; 33: 253-257.

Department of General Surgery, Marmara University School of Medicine, İstanbul, Turkey

This study was presented at the $20^{\text {th }}$ National Congress of Surgery, 13-17 April 2016, Antalya, Turkey.

Address for Correspondence
Aylin Erdim
e-mail: aerdim1@hotmail.com
Received: 10.05 .2016
Accepted: 04.09 .2016
OCopyright 2017
by Turkish Surgical Association
Available online at
www.turkjsurg.com

Aylin Erdim

e-mail:aerdim1@hotmail.com

Available online at

www.turkjsurg.com
Objective: This study was designed to evaluate the perioperative nutritional status of patients undergoing surgery for gastrointestinal cancer using Subjective Global Assessment and surgeon behavior on nutritional support.

Material and Methods: We recruited 100 patients undergoing surgery for gastrointestinal cancer in one university and two state teaching hospitals. Subjective Global Assessment was administered to evaluate preoperative and postoperative nutritional status. Fifty-two patients in the state hospitals (Group 1) and 48 in the university hospital were assessed. Anthropometric and biochemical measurements were performed. Changes in preoperative Subjective Global Assessment scores and scores at the time of discharge and types of nutritional support were compared. Subjective Global Assessment-B was regarded as moderate and Subjective Global Assessment-C as heavy malnutrition.

Results: Ten patients had Subjective Global Assessment-B and 29 had Subjective Global Assessment-C malnutrition in Group 1 and nine had Subjective Global Assessment-B and 31 had Subjective Global Assessment-C malnutrition in Group 2 during preoperative assessment. Respective numbers in postoperative assessment were 12 for Subjective Global Assessment-B and 30 for Subjective Global Assessment- $C$ in Group 1 and 14 for Subjective Global Assessment-B and 26 for Subjective Global Assessment-C in Group 2. There was no difference between two groups. Nutritional methods according to Subjective Global Assessment evaluation in pre- and postoperative periods were not different between the groups.

Conclusion: This study demonstrated that the malnutrition rate is high among patients scheduled for gastrointestinal cancer surgery and the number of surgeons were inadequate to provide perioperative nutritional support. Both university and state hospitals had similar shortcomings. Subjective Global Assessment is an easy and reliable test and if utilized will be helpful to detect patients requiring nutritional support.

Keywords: Gastrointestinal cancer, malnutrition, perioperative nutrition, subjective global assessment

\section{INTRODUCTION}

An organism should maintain its physiological and metabolic functions to sustain healthy life. Adequate and balanced nutrition is a priority for the regular maintenance of these functions. An organism becomes more sensitive to malnutrition particularly during times of illness (1,2). In surgical patients, malnutrition rates vary between $22 \%$ and $54 \%$ due to various parameters such as age, sex, and current illness (3). Increased incidence of infections, liquid-electrolyte disturbances, and decline in functional status may accompany malnutrition (4-6). Operated patients with malnutrition are at increased risk of mortality and have higher complication rates and prolonged hospital stays; this condition also prolongs the period of rehabilitation and recovery. Thus, surgical patients should be screened for nutritional status and perioperative nutritional support should be provided for patients with malnutrition $(4,7,8)$. In a study by Hill et al. (9), it was determined that $40 \%$ of medical patients and $50 \%$ of surgical patients had malnutrition and that these rates increased as hospital stays lengthened. Research on what type of nutrition should be recommended is still proceeding $(6,10,11)$.

Assessment of patients' nutritional status should be conducted by a multidisciplinary team. This team should include doctors, nurses, dietitians, and social workers. Nurses are among health personnel who mostly contact and communicate with patients, and therefore, nurses have an important role in terms of detecting patients who need nutritional support $(12,13)$. Various methods are used for determining the level of malnutrition. Subjective Global Assessment (SGA) is based on patient history and physical examination findings. SGA is easy to use and has high accuracy rates, which increase its clinical utilization. SGA was developed to assess physiological symptoms of malnutrition or conditions related to malnutrition and to assess functional capacity (Appendix) $(1,2,5,12,14)$. Patients with gastrointestinal (GIS) cancer frequently have nausea, vomiting, lack of appetite, and malabsorption; therefore, malnutrition is more common among such patients who will be undergoing surgery.

The current study aimed to assess nutritional status in the perioperative period using the SGA method in patients undergoing GIS cancer surgery at a university hospital and two state training and research hos- 
pitals and to determine malnutrition rates and the proportion of patients with malnutrition who will benefit with nutritional support. It was also investigated whether there were differences with regard to patient profiles and nutritional behavior of patients between the university hospital and other training and research hospitals.

This study was based on the hypothesis that surgeons could not provide adequate nutritional support for patients during the perioperative period.

\section{MATERIAL AND METHODS}

The study was conducted in 2007 at the Marmara University Hospital General Surgery Service, Göztepe Training and Research Hospital $4^{\text {th }}$ Surgical Service, and Lütfi Kırdar Kartal Training and Research Hospital Surgical Service. Patients undergoing GIS surgery were recruited. Nutritional status of the patients during the perioperative period was assessed using SGA and patients receiving nutritional support were noted (Appendix).

To conduct the subjective assessment, patient medical history was noted and physical findings were investigated based on the form presented in Appendix. In the history section, the assessment was conducted according to the titles that investigate the change in body weight within the last 6 months $(<5 \%, 5-10 \%$, or $>10 \%$ loss), change in nutritional intake, GIS symptoms (e.g., lack of appetite, nausea, vomiting, and diarrhea), and functional capacity. As a result of the assessment, each feature is scored as A (normal or good nutrition), B (mild-moderate malnutrition), or $C$ (severe malnutrition). In terms of physical examination, loss of subcutaneous fat tissue over the mid-axillary line of the lateral chest walls (axillary skinfold thickness=AST) and triceps (triceps skinfold thickness=TST), loss of muscle mass (over the deltoid and quadriceps areas), and presence of edema (ankles, sacral region, or ascites) were assessed and each feature was scored as $0=$ normal, $1+=$ mild, $2+=$ moderate, and $3+=$ severe. After scoring history and physical examination data, patients were classified by researcher who conducted the assessment as follows: good nutritional status (A), mild-to-moderate impairment in nutritional status (B), and severe impairment in nutritional status (C). In order to standardize the assessment, SGA was conducted and scored by the same researcher on the first day of hospitalization at the surgical service and on the day of discharge (after 5-10 days). According to this assessment procedure, patients who had a score of SGA-A were accepted to have adequate nutritional status.

After receiving permission from the Marmara University School of Medicine Ethics Committee to carry out the study, approval for conducting the study at the Göztepe Training and Research Hospital and the Lütfi Kırdar Training and Research Hospital was obtained from the Provincial Directorate of Health. Patients who were undergoing surgery for colon or stomach cancer, who were aged between 18 and 65 years, who were at least elementary school graduates, who had no barriers to communication, who did not undergo GIS surgery 6 months prior to treatment, who did not have additional malignities to stomach or colon cancer, and who agreed to participate were included in the study. Patients not meeting these criteria were excluded from the study.

After obtaining consent from all study patients, nutritional status in the pre- and post-operative period was determined using SGA. According to this assessment, SGA-B and SGA-C patients were accepted to have malnutrition.

\begin{tabular}{|c|c|c|c|c|c|c|}
\hline \multirow{2}{*}{\multicolumn{2}{|c|}{$\begin{array}{l}\text { Descriptive patient } \\
\text { characteristics }\end{array}$}} & \multicolumn{2}{|c|}{ (Group 1) $(n=52)$} & \multicolumn{2}{|c|}{ (Group 2$)(n=48)$} & \multirow[b]{2}{*}{$\mathbf{p}$} \\
\hline & & $\mathbf{n}$ & $\%$ & $\mathbf{n}$ & $\%$ & \\
\hline \multicolumn{2}{|c|}{ Mean age (min-maximum) } & 49 & $(39-65)$ & 54 & $(37-65)$ & 0.080 \\
\hline \multicolumn{2}{|l|}{ Height (cm) } & 167 & $(154-185)$ & 162 & $(155-188)$ & 0.190 \\
\hline \multicolumn{2}{|c|}{ Body weight at hospitalization (kg) } & 61 & $(48-78)$ & 59 & $(45-82)$ & 0.125 \\
\hline \multirow[t]{2}{*}{ Gender } & Female & 23 & 44 & 23 & 48 & 0.712 \\
\hline & Male & 29 & 56 & 25 & 52 & \\
\hline \multirow[t]{2}{*}{ Marital status } & Married & 44 & 85 & 45 & 94 & 0.145 \\
\hline & Single & 8 & 15 & 3 & 6 & \\
\hline \multirow[t]{3}{*}{ Educational status } & Elementary school & 13 & 25 & 14 & 29 & 0.877 \\
\hline & Middle school & 29 & 56 & 26 & 54 & \\
\hline & Higher education & 10 & 19 & 8 & 17 & \\
\hline \multirow[t]{2}{*}{ Employment status } & Unemployed & 21 & 40 & 21 & 44 & 0.733 \\
\hline & Employed & 31 & 60 & 27 & 56 & \\
\hline \multirow[t]{2}{*}{ Health insurance } & Present & 47 & 90 & 46 & 96 & 0.286 \\
\hline & None & 5 & 10 & 2 & 4 & \\
\hline \multirow[t]{2}{*}{ Smoking status } & Smoking & 27 & 52 & 29 & 60 & 0.393 \\
\hline & Not smoking & 25 & 48 & 19 & 40 & \\
\hline Previous operations & Yes & 14 & 27 & 7 & 15 & 0.130 \\
\hline
\end{tabular}


The personal characteristics [such as age, height, body weight, body mass index (BMI), marital status, educational and employment status, health insurance, and smoking status] of the patients were also recorded. Loss of weight in the past 6 months was also questioned. On the day of discharge, SGA was repeated by the researcher. Patients were also assessed for provided nutritional support and malnutrition.

\section{Statistical Analysis}

Data was evaluated using the Statistical Package for the Social

Table 2. Comparison anthropometric measurements and biochemical parameters affecting nutritional status

\begin{tabular}{|lccc|}
$\begin{array}{l}\text { Anthropometric } \\
\text { measurements and } \\
\text { biochemical parameters }\end{array}$ & $\begin{array}{c}\text { (Group 1) } \\
(\mathbf{n}=52)\end{array}$ & $\begin{array}{c}\text { (Group 2) } \\
(\mathbf{n}=48)\end{array}$ & $\mathbf{p}$ \\
\hline Loss of body weight $(\mathrm{kg})$ & $7.7 \pm 2.8$ & $8.5 \pm 2.1$ & 0.197 \\
\hline Body mass index (BMI) $\left(\mathrm{kg} / \mathrm{m}^{2}\right)$ & $21.7 \pm 2.2$ & $19.0 \pm 1.8$ & 0.001 \\
\hline $\begin{array}{l}\text { Triceps skinfold thickness } \\
\text { (TST) (mm) }\end{array}$ & $17.0 \pm 4.2$ & $15.5 \pm 2.9$ & 0.03 \\
\hline $\begin{array}{l}\text { Middle upper arm } \\
\text { circumference (MUAC) (cm) }\end{array}$ & $26.9 \pm 1.3$ & $26.3 \pm 1.3$ & 0.15 \\
\hline $\begin{array}{l}\text { Middle upper arm muscle } \\
\text { circumference (MUAMC) }(\mathrm{cm})\end{array}$ & $22 \pm 2.7$ & $21 \pm 2.5$ & 0.001 \\
\hline Total Protein (g/dL) & $5.9 \pm 0.8$ & $5.7 \pm 0.5$ & 0.07 \\
\hline Albumin (g/dL) & $4.05 \pm 0.6$ & $3.7 \pm 0.4$ & 0.001 \\
\hline Prealbumin (g/dL) & $0.2 \pm 0.01$ & $0.16 \pm 0.01$ & 0.289 \\
\hline Hemotocrit (Hct) \% & $36.7 \pm 3.5$ & $35 \pm 3.0$ & 0.02 \\
\hline Hemoglobin (Hgb) (g/dL) & $9.6 \pm 1.2$ & $8.7 \pm 1.0$ & 0.02 \\
\hline
\end{tabular}

*Data was interpreted according to means, \pm SD, number $(n)$ and 0.05 significance level
Sciences version 17.0 (SPSS Inc.; Chicago, IL, USA) software. Values of $p<0.05$ were accepted to be statistically significant. Independent groups were analyzed using the chi-square test and the Mann-Whitney $U$ test, while dependent groups were compared using the student $t$ test.

\section{RESULTS}

A total of 52 patients were recruited from training and research hospitals (Group 1), while 48 patients were recruited from the university hospital (Group 2). Descriptive characteristics of the patients are presented in Table 1. It was found that the two groups were similar and that there were no significant differences between them. Examination of anthropometric measurements and biochemical parameters that determined patients' preoperative nutritional status revealed that patients in Group 1 had significantly better nutritional parameters than patients in Group 2 (Table 2). Mean loss of weight in the past 6 months was $7.7 \pm 2.8 \mathrm{~kg}$ in Group 1 and $8.5 \pm 2.1$ in Group 2 ( $p>0.05$ ). It was determined that patients in Group 1 had a mean BMI of 21.7 \pm 2.2 $\mathrm{kg} / \mathrm{m}^{2}$, while patients in Group 2 had a mean BMI of $19.0 \pm 1.8$ $\mathrm{kg} / \mathrm{m}^{2}(\mathrm{p}<0.001)$.

It was found that patients in Group 1 had a mean TST of $17.02 \pm 4.2 \mathrm{~mm}$, whereas patients in Group 2 had a mean TST of $15.5 \pm 2.9 \mathrm{~mm}(p<0.05)$. Examination of mid-upper arm circumference (MUAC) showed that patients in Group 1 had a mean MUAC of $26.9 \pm 1.3 \mathrm{~cm}$, whereas patients in Group 2 had a mean MUAC of $26.3 \pm 1.3 \mathrm{~cm}(p<0.05)$. It was determined that patients in Group 1 had a mean mid-upper arm muscle circumference (MUAMC) of $22 \pm 2.7 \mathrm{~cm}$, whereas patients in Group 2 had a mean MUAMC of $21 \pm 2.5 \mathrm{~cm}$ and that the difference between the two groups was highly significant $(p<0.001)$.

Examination of albumin values revealed that patients in Group 1 had a mean value of $4.05 \pm 0.6 \mathrm{~g} / \mathrm{dL}$, whereas patients in Group 2 had a mean value of $3.7 \pm 0.4 \mathrm{~g} / \mathrm{dL}(\mathrm{p}<0.001)$. Patients in Group

Table 3. Comparison of the distribution of pre- and post-operative nutrition types according to the localization of disease in Group 1 and Group 2

\begin{tabular}{|c|c|c|c|c|c|c|}
\hline \multirow[t]{2}{*}{ Preoperative nutrition type } & \multicolumn{3}{|c|}{ (Group 1) $(n=52)$} & \multicolumn{3}{|c|}{ (Group 2$)(n=48)$} \\
\hline & $\begin{array}{c}\text { SGA-A } \\
n\end{array}$ & $\begin{array}{c}\text { SGA-B } \\
n\end{array}$ & $\begin{array}{c}\text { SGA-C } \\
n\end{array}$ & $\begin{array}{c}\text { SGA-A } \\
n\end{array}$ & $\begin{array}{c}\text { SGA-B } \\
n\end{array}$ & $\begin{array}{c}\text { SGA-C } \\
n\end{array}$ \\
\hline Enteral & 2 & 3 & 9 & 4 & 1 & 6 \\
\hline Parenteral & - & 1 & 2 & 1 & 3 & 10 \\
\hline Enteral+parenteral & - & - & 2 & - & 4 & 11 \\
\hline Nutrition via oral route & 11 & 6 & 16 & 3 & 1 & 4 \\
\hline Total & 13 & 10 & 29 & 8 & 9 & 31 \\
\hline \multirow[t]{2}{*}{ Postoperative nutrition type } & \multicolumn{3}{|c|}{ (Group 1) $(n=52)$} & \multicolumn{3}{|c|}{ (Group 2) $(n=48)$} \\
\hline & $\begin{array}{c}\text { SGA-A } \\
n\end{array}$ & $\begin{array}{c}\text { SGA-B } \\
n\end{array}$ & $\begin{array}{c}S G A-C \\
n\end{array}$ & $\begin{array}{c}\text { SGA-A } \\
n\end{array}$ & $\begin{array}{c}\text { SGA-B } \\
n\end{array}$ & $\begin{array}{c}\text { SGA-C } \\
n\end{array}$ \\
\hline Enteral & 2 & 2 & 4 & 4 & 2 & 3 \\
\hline Parenteral & 7 & 6 & 10 & 3 & 6 & 8 \\
\hline Enteral+parenteral & 1 & 3 & 12 & 1 & 5 & 14 \\
\hline Nutrition via oral route & - & 1 & 2 & - & 1 & 1 \\
\hline Total & 10 & 12 & 30 & 8 & 14 & 26 \\
\hline
\end{tabular}


Erdim and Aktan.

Evaluation of perioperative nutritional status with subjective global assessment

1 had a mean prealbumin value of $0.2 \pm 0.01 \mathrm{~g} / \mathrm{dL}$ and patients in Group 2 had a mean value of $0.16 \pm 0.01 \mathrm{~g} / \mathrm{dL}(\mathrm{p}>0.05)$.

It was found that patients in Group 1 had a mean hematocrit (Hct) value of $36.7 \pm 3.5 \%$ and patients in Group 2 had a mean value of $35 \pm 3.0 \%(p<0.05)$. Patients in Group 1 had a mean hemoglobin $(\mathrm{Hgb})$ value of $9.6 \pm 1.2 \mathrm{~g} / \mathrm{dL}$, whereas patients in Group 2 had a mean value of $8.7 \pm 1.0 \mathrm{~g} / \mathrm{dL}(\mathrm{p}<0.05)$. Among patients in Group 1, 12 of 15 patients with stomach cancer (80\%), 16 of 18 with colon cancer (88.9\%), 11 of 19 with rectal cancer $(57.9 \%)$, and 39 of 52 in total (75\%) were determined to have malnutrition during preoperative assessment. In Group 2, 8 of 10 patients with stomach cancer (80\%), 19 of 22 with colon cancer $(86.3 \%), 13$ of 16 with rectum cancer $(81.2 \%)$, and 40 of 48 in total $(83.3 \%)$ had malnutrition. There was no difference in malnutrition rates between the two groups.

Examination of postoperative values revealed that 35 of 52 patients in Group 1 (67.3\%) and 19 of 48 patients in Group 2 (39.6\%) had malnutrition. Examination of nutrition types according to preoperative SGA values showed that 2 of 13 patients at SGA-A level in Group 1 received enteral, parenteral, or enteral+parenteral nutritional support (15.4\%), whereas 4 of 10 patients at SGA-B level (40\%) and 13 of 29 patients at SGA-C level (44.8\%) received nutritional support. In Group 2, $62.5 \%$ of SGA-A patients, $88.9 \%$ of SGA-B patients, and $87.1 \%$ of SGA-C patients received nutritional support (Table 3). It was determined that there was no significant difference between the groups. The adequacy of nutritional support provided for the patients was not investigated. Examination of nutrition types according to postoperative SGA values revealed that all 10 patients at SGA-A level in Group 1 (100\%), 11 patients out of 12 at SGA-B level (91.6\%), and 28 patients out of 30 at SGA$C$ level (93.3\%) received nutritional support. In Group 2, all 8 patients at SGA-A level (100\%), 13 patients out of 14 at SGA-B level (92.8\%), and 25 patients out of 26 at SGA-C level (96.2\%) received nutritional support (Table 3 ). There was no significant difference between the groups.

\section{DISCUSSION}

In the current study, which assessed preoperative nutritional status of patients undergoing GIS surgery using the SGA method and examined the rate of nutritional support provided, 52 patients operated in training and research hospitals (Group 1) and 48 patients in the general surgery clinic of a university hospital (Group 2) were compared. Although the demographic characteristics of the two groups were similar, patients staying at the university hospital had significantly worse anthropometric measures. A number of values, notably $\mathrm{BMI}$ and $\mathrm{Hgb}$ and $\mathrm{Hct}$ values were lower in patients undergoing surgery at the university hospital. Because university hospitals have better equipment and medical staff, these patients may have been referred to this hospital in particular. However, due to increased patient complaints and law suits in recent years, doctors tend to avoid problematic patients and may refer these patients to a university hospital clinic. Such a difference between two institutions both of which provide tertiary healthcare services indicates that defensive medicine is more commonly practiced at training and research hospitals.

In preoperative assessment, 39 patients out of 52 in Group 1 (75\%) and 40 patients out of 48 in Group 2 (83.3\%) were found to have malnutrition. There was no difference in malnutrition rates between the two groups. However, high malnutrition rates indicate that patients who present with GIS cancers in our country are diagnosed late due to various reasons and that a large group of patients need nutritional support during treatment. An even more surprising finding of the current study is that 29 patients out of 39 with malnutrition in Group 1 and 31 of 40 patients with malnutrition in Group 2 had severe malnutrition (SGA-C). These findings demonstrated that patients undergoing surgery for malignant disease need nutritional support at extreme levels. The research hospitals were public hospitals, and therefore, they have a specific patient profile. Among 100 patients in both groups, 82 were elementary and middle school graduates. In these patients, late diagnosis has a negative impact on nutritional status. In patients undergoing surgery for GIS malignity, in particular, nutritional status has a key role in surgical outcomes (14). Thus, the purpose of determining preoperative nutritional status is to detect high-risk patients and provide an appropriate nutritional regime. Numerous studies have shown that SGA gives accurate results in detecting malnutrition and that it is as reliable as other methods.

Although malnutrition rates are very high in patients undergoing GIS surgery for malignant disease, nutritional support provided for these patients was well below expected rates. In preoperative assessment, 20 SGA-C patients in both groups did not receive any type of nutritional support prior to surgery. One-third of 60 patients with severe malnutrition in both groups did not receive any nutritional support. Adequacy of nutritional support provided for other patients was not investigated. Postoperative nutritional support was better compared with the preoperative period; however, it was found that 3 SGA$C$ patients in both groups did not receive any nutritional support. Pre- and postoperative nutritional support practices did not differ between the general surgery clinic of the university hospital and the two training and research hospitals. One of the reasons of inadequate nutritional support may be that none of the study hospitals had nutrition units. There are also recent studies indicating that this problem is still continuing (15). It was concluded that nutritional support was rarely provided in the preoperative period. According to the European Society for Clinical Nutrition and Metabolism (ESPEN) guidelines, surgery may be postponed in patients under risk for malnutrition or in patients predicted to experience inadequate oral intake, although there is no present malnutrition; further, enteral nutritional support is recommended $10-14$ days prior to surgery $(16,17)$. In a study that recruited patients with GIS cancer and malnutrition, nutritional support provided 7-10 days prior to surgery and continued after the surgery reduced complication rates compared with postoperative standard intravenous liquid administration (18). Gencosmanoglu et al. (19) reported that enteral feeding via a nasojejunal tube during the early postoperative period in patients with stomach cancer who underwent total gastrectomy surgery has low morbidity rates and is easy to use. In the literature, it has been reported that parenteral feeding may be an effective alternative if malnutrition is present and enteral feeding cannot be tolerated or if GIS cannot function (20).

\section{CONCLUSION}

The current study determined that malnutrition rates were very high in patients undergoing GIS surgery for malignant diseases and that surgeons could not provide adequate nu- 
tritional support for patients with severe malnutrition during the preoperative period. Nutritional practices were found to be similar in state teaching hospitals and in the university hospital. Because SGA is a simple and easy-to-use method, its routine administration during the preoperative period would help identify patients who need nutritional support.

Ethics Committee Approval: Ethics committee approval was received for this study from the ethics committee of Marmara University Institute of Health Science and İstanbul provincial health directorate.

Informed Consent: Written informed consent was obtained from patients who participated in this study.

Peer-review: Externally peer-reviewed.

Author Contributions: Concept - A.E., A.Ö.A.; Design - A.E., A.Ö.A.; Supervision - A.E, A.Ö.A.; Resource - A.E., A.Ö.A.; Materials - A.E., A.Ö.A.; Data Collection and/or Processing - A.E., A.Ö.A.; Analysis and/or Interpretation - A.E., A.Ö.A.; Literature Search - A.E., A.Ö.A.; Writing Manuscript - A.E., A.Ö.A.; Critical Reviews - A.E., A.Ö.A.

Conflict of Interest: No conflict of interest was declared by the authors.

Financial Disclosure: The authors declared that this study has received no financial support.

\section{REFERENCES}

1. Gündoğdu H. Nutritional support in surgical patients. Cerrahi Tıp Bilimleri Derg; 2000; 3: 2-3.

2. Kılıçturgay S. Evaluation of nutritional deficiencies and indications of administration. T Klin J Surg 1998; 3: 81-94.

3. Bruun LI, Bosaeus I, Bergstad I, Nygaard K. Prevalence of malnutrition in surgical patients: evaluation of nutritional support and documentation. Clin Nutr 1999; 18: 141-147. [CrossRef]

4. Stanga Z, Allison S. Nutrition in elderly. In: Clinical nutrition: Basic concepts. L. Sobatka ed., (Translation ed. M. Bahar), Logos Publishing, İstanbul 2002; 226-245.

5. Koç M. Clinical nutrition. Nutritional Support Therapy 2000; 1928.
6. Başaran GA. Nutrition in cancer patients. Klinik Gelişim 2004; 17: 24-32.

7. Değerli Ü. Genel cerrahi. Emre A. Nutrition in surgery. 5th edition. Nobel Tıp Kitapevi. İstanbul,1995;103-10.

8. Tufan T, İnanç N, Oğuz S, Saka M, Dağ B, Şafak H. Enteral nutritional supplement therapy. Ed. Tufan T, İnanç N, Oğuz S, Saka M, Dağ B, Şafak H. Gülhane Askeri Tıp Akademisi: GATA, Ankara. 2003.p.34.

9. Hill GL, Blackett RL, Pickford I, Burkinshaw L, Young GA, Warren JV et al. Malnutrition in surgical patients. An unrecognised problem. Lancet 1977; 1: 689-692. [CrossRef]

10. Clinical Nutrition basic concepts, ESPEN courses publishing editor Group: KEPAN board of directors, 2nd edition, 2002.

11. Allison SP. Malnutrition, disease and outcome. Nutrition 2000; 16 : 590-593. [CrossRef]

12. Detsky AS, McLaughlin JR, Baker JP, Johnston N, Whittaker S, Mendelson RA, et al. What is Subjectif-Global assesment of nutritional status? J Parenteral Enteral Nutr; 1987: 11: 8-13. [CrossRef]

13. Kruizenga HM, Seidell JC, de Vet HC, Wierdsma NJ, van Bokhorstde van der Schueren MA. Development and validation of a hospital screening tool for malnutrition:the short nutritional assessment questionnaire (SNAQ). Clin Nutr2005; 24: 75-82. [CrossRef]

14. Zeybek $N$, Turgut $T$, Şen $D$. Evaluation of feeding in emergency patients Ed. Koçar H, Erikçi S, Baykal Y, Acil Iç Hastalıkları, GATA, Etlik Ankara, 2003, p:700-722.

15. Weimann $A$, Braga $M$, Harsanyi L, Laviano A, Ljungqvist $O$, Soeters $P$, et al. ESPEN Guidelines on Enteral Nutrition: Surgery including organ transplantation. Clinical Nutrition 2006; 25: 224-244. [CrossRef]

16. Başkonuş I, Borazan E, Maralcan G, Aybastı N, Gökalp A, Balık A.A, Perioperative total parenteral nutrition effects on postoperative morbidity and mortality, Gaziantep Tıp Dergisi 2011; 17: 141-146.

17. Kılıç KM, Kızılarslanoğlu CM, Toruk E, Çevik I, Demir H, Altun $H_{\text {, }}$ et al. Effect on age nutritional support parameters in patients followed in a university hospital nutrition support unit. Iç Hastalıkları Dergisi 2014; 21: 33-39.

18. Bozetti F. Perioperatif nutrition of patients with gastrointestinal cancer. Br J Surg 2002; 89:1201-1202. [CrossRef]

19. Gençosmanoğlu R, Koç D, İnceoğlu R. Early postoperative enteral nutrition after total gastrectomy. Klinik ve Deneysel Cerrahi 2000; 8: 194-197.

20. Jeejeebhoy KN. Total parenteral nutrition: potion or poison? Am J Clin Nutr 2001; 74: 160-163. 


\section{A. History}

\section{Weight change}

Overall loss in past 6 months: amount: $\mathrm{kg}$

$\%$ loss:

Change in past 2 weeks:

decrease, increase, no change

2. Dietary intake change

a. No change

b. Change duration: weeks type: ....... suboptimal liquid diet full liquid diet hypocaloric liquids starvation

3. Gastrointestinal symptoms (that persisted for $>\mathbf{2}$ weeks)

a. None

b. There is nausea vomiting anorexia diarrhea

4. Functional capacity

a. No dysfunction

b. Dysfunction duration weeks

c. Working suboptimally ambulatory bedridden

\section{Disease and its relation to nutritional requirements}

a. Primary diagnosis .

b. Metabolic demand (stress): No stress Low stress Moderate stress High stress

B. Physical (for each trait specify: $\mathbf{0 = n o r m a l , ~ 1 + = m i l d , ~ 2 + = m o d e r a t e , ~} \mathbf{3 + = s e v e r e ) ~}$

a. Loss of subcutaneous fat triceps and chest:

b. Muscle wasting (quadriceps, deltoid ve temporal):

c. Ankle edema and sacral edema:

d. Ascites:

e. Skin and tongue lesions with food deficiencies:

\section{SGA rating (select one)}
a. Well-nourished
b. Moderately malnourished
c. Severely malnourished

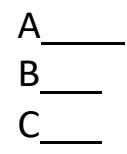

